\title{
Developing Experience-Based Premium Rate Discounts in Crop Insurance
}

\author{
Roderick M. ReJesus, KEITH H. Coble, \\ Thomas O. KNIGHT, AND YufeI JiN
}

\begin{abstract}
This article addresses the feasibility of implementing an experience-bosed premium rate discount system in crop insurance. While adverse selection and moral hazard in crop insurance have been extensively studied in the past, discount systems or bonus-malus incentives have not, to our knowledge, been investigated. Our empirical analysis indicates that a crop insurance discount system could be implemented based on a measure of favorable past insurance experience. The estimated average discounts based on the rating methods developed in this study ranged from $5 \%$ to $9 \%$ (depending on the crop being considered).
\end{abstract}

Key words: bonus-malus, crop insurance, discounts, good experience, insurance rating.

The issue of providing premium rate cliscounts based on favorable insurance experience has been in the economic literature since the early 1980 s. $^{1}$ These premium rate discounts are usually justified by the presence of asymmetric information between the policyholders and the insurers (i.e., adverse selection and moral hazard). Premium rate discounts based on past insurance performance are a way of adjusting the insurance contract to better reflect the policyholder's risk and reduce asymmetric information problems due to adverse selection (Boyer and Dionne, 1989; Dionne and Vanasse, 1989, 1992). A premium rate cliscount system based on favorable experience also makes it possible to maintain proper incentives (over time) to reduce the inefficiencies associated with moral hazard (Arnott, 1992; Winter, 2000).

Raderick M. Rejesus and Thomas O. Knight are assistunt professor and prolessor. respectively, Department of Agricultural and Applitul Economics, Texas Tech University. Keith H. Coble is associate professor. Department of Agricultural Economics, Misssissippi State Universily. Yufei Jin is economist, AGRICORP, Canuda.

Tlis research was funded in part by USDA-RMA (Contract No. GS-23F-0135K). Note that the views herein are of the attlors and not necessurily of RMA. The authors would like to thunk Barry Goodwin, Wade Brorsen, and two anonymous reviewers for their helpful comments. Any remuining errors are the authors".

'See Lemaire (1995) for a description of different discount/ surchurge sebemes bised on itsurance experience. Recent studies about premium rate discounts are typically studied in the context of automobile insurance (see, e.g. Kilger and Levikson. 20)f?: Bermudez, Denuit. and Dluete, 2(00) bile insurance literature, these discount/surcharge systents atre usually called bonus-malus schemes or experience rating schemes. A theoretical treatment of experienct rating scltemes ctn be seen in Pinqutet (2toio) and Lemaire (1995).
Though premium rate discount schemes have been in place in other insurance markets and have been empirically studied in the past (see Dionne and Vanasse, 1992; Dionne and Ghali, 2003), an experience-based premium rate discount has not, to our knowledge, been investigated for the U.S. Federal Crop Insurance Program. Various crop insurance studies have examined the issue of rate making (see, e.g., Ker and McGowan, 2000; Goodwin, 1994; Ker and Goodwin, 2000), but most of these studies have focused on the effects of current rate-making procedures on adverse selection and moral hazard, not on developing discount or bonus-malus type systems that could mitigate these asymmetric information problems.

Goodwin and Smith (1995), for example, indicated that there is considerable evidence of adverse selection in the program and that adverse selection is a direct consequence of insurers' inability to set premiums commensurate with the level of risk. Hence, a preponderance of studies have attempted to address the adverse selection problem by improving current rate-making procedures (Goodwin, 1994; Ker and Goodwin, 2000). Coble et al. (1997) also found that moral hazard significantly affects the actuarial soundness of the program. Suggested approaches to remedy the moral hazard problem have typically involved partial insurance coverage and/or various monitoring procedures (Turvey, Hoy, and Islam, 2002; Hyde and Vercammen, 1997). Note, however, that there has been no study that suggested the use of a discount system as a potential approach to 
"typical" cases but leads to extreme and unacceptable outcomes in some small percentage of cases. By examining these outcomes, any need for caps, cups, or other constraints are revealed. Overall, the median discount factors are very similar to the mean discount factors for all crops. However, there is significant variation in the estimated discount factors at the various percentiles, both at the national and regional levels. An important observation here is the apparent asymmetric distribution of the discount factors in corn, soybeans, and wheat, while the distribution of the discount factors for cotton seems to be more symmetric. This suggests that among the "good"producers who qualify for a discount, there tend to be more producers at the upper end of the distribution for corn, soybeans, and wheat (i.e., there are more "good" producers for these crops that deserve to get a large discount).

Analyzing the proportion of individual observations qualifying and receiving a discount would also give more perspective as to the potential impact of the proposed discount system. Note that individual producers will only qualify for the discount if they have at least five years of continuous participation in the program (due to the $L R I$ calculation). The qualifying producer can then receive a discount if his/her $L R I$ is below the 1.0 threshold. Using the data for the whole nation, the proportions of producers that qualify for a discount under our system are $13.7 \%, 13.4 \%, 14.1 \%$, and $8.2 \%$ for corn, soybeans, cotton, and wheat, respectively. Furthermore, the proportions of producers that would actually receive a "good" experience discount because of an $L R I<1.0$ are $10.2 \%, 10.3 \%, 8.7 \%$, and $5.6 \%$ for corn, soybeans, cotton, and wheat, respectively.

\section{Conclusions}

This article determines the feasibility of implementing an experience-based discount system in crop insurance as well as the methodological issues involved in constructing it. Our estimation results indicate that the best measure of good experience is relative historical loss experience. Using the $L R I$ as a measure of relative historical loss experience, the estimated mean/median discounts for qualifying producers are approximately $10 \%$ for corn and soybeans, and in the $5 \%$ to $6 \%$ range for cotton and wheat.

Since the results of the loss ratio models (using the $L R I$ experience measure) showed statistical significance of the $L R I$ parameters in all cases, this suggests that an appropriate experience-based measure has some power in explaining individual loss experience. Hence, a system of rating that includes a performance- or experience-based discount will provide more accurate rates for producers receiving the discount and will improve actuarial soundness of the program. Currently participating low-risk producers who perceive that they are being overcharged relative to their experience (i.e., due to adverse selection) would then likely view the program more favorably if such a discount system is in place. Low-risk producers that are not participating in the program may also be encouraged to purchase crop insurance in light of the possibility of receiving discounts for betterthan-average performance. In addition, the proposed experience-based premium rate discount can also improve program integrity by providing incentives to maintain good historical loss experience. Producers would recognize that there is a long-run benefit in maintaining loss experience that is better than average for their peer group. Hence, incentives for moral hazard may be minimized. This would counterbalance a number of behaviors that tend to undermine program integrity and actuarial soundness.

Although there are some detailed implementation issues that need to be addressed (i.e., policy language, reporting requirements, revised premium rate calculator), we believe that the experience-based premium rate discount structure proposed here can be implemented by the RMA because of the straightforward calculations needed to generate the multiplicative discount factors. Pilot programs in order to observe actual performance and impacts of the proposed system may be the logical next step to assess its feasibility and appropriateness.

\section{[Received September 2004; accepted July 2005.]}

\section{References}

Arnott, R.J. 1992. "Moral Hazard and Competitive Insurance Markets." In G. Dionne, ed. Contributions to Insurance Economics. Boston: Kluwer Academic Press, pp. 325-59.

Bermudez, L., M. Denuit, and J. Dhaene. 2001. "Exponential Bonus-Malus Systems Integrating A Priori Risk Classification."Joumal of Actuarial Practice 9:84-112. 
Boyer, M., and G. Dionne. 1989. "An Empirical Analysis of Moral Hazard and Experience Rating." Review of Economics and Statistics 71:215-76.

Coble, K.H., T.O. IKright, R.D. Pope, and J.R. Williams. 1997. "An Expected Indemnity Approach to the Measurement of Moral Hazard in Crop Insurance." American .Joumal of Agricultural Economics 79:21626.

De Wit, G.W., and J. Van Eeghen. 1984. "Rate Making and Society's Sense of Fairness." ASTIN Bulletin 14:13-27.

Dionne, G., and O. Ghali. 2003. "The (1992) BonusMalus System in Tunisia: An Empirical Evaluation." HEC Montreal Working Paper 2003-07, HEC Montreal, Canada.

Dionne, G., and C. Vanasse. 1989. "A Generalization of Automobile Rating Models: The Negative Binomial Distribution with a Regression Component." ASTIN Bulletin 19:199212.

1992. "Automobile Insurance Ratemaking in the Presence of Asymmetrical Information." Journal of Applieal Econontetrics 7:14965.

Goodwin, B.K. 1994. "Premium Rate Determination in the Federal Crop Insurance Program: What Do Averages Have to Say About Risk?" Journal of Agricultural and Resource Econonics 19:38?-95.

Goodwin, B.K., and V.H. Smith. 1995. The Economics of Crop Insurance and Disaster Aid. Washington DC: American Enterprise Institute.

Greene, W. 2003. Econontric Analysis, 5th ed. Upper Saddle River, NJ: Prentice Hall.

Hyde, C.E., and J.A. Vercammen. 1997. "Costly Yield Verification, Moral Hazard, and Crop Insurance Contract Form." Joumal of Agricultural Economics 4s:393-407.

Ker, A.P., and B.K. Goodwin. 2000. "Nonparametric Estimation of Crop Insurance Rates
Revisited." American Joumal of Agricultural Econonics 83:463-78.

Ier, A.P., and P. McGowan. 2000. "Weather-Based Adverse Selection and the U.S. Crop Insurance Program: The Private Instrance Company Perspective." Joumal Agricultural and Resource Economics 25:386-410.

Kilger, D., and B. Levikson. 2002. "Pricing No Claims Discount Systems." Insurance: Mathematics and Economics 31:191-204.

Knight, T.O., and K.H. Coble. 1997. "Survey of U.S. Multiple Peril Crop Insurance Literature Since 1980." Review of Agricultural Economics 19:128-56.

Lemaire, J. 1995. Bonus-Malus Systems in Automobile Insurance. Boston: Kluwer Academic Publishers. .

Milliman and Robertson, Inc. 2000. Actuarial Docunnentation of Multiple Peril Crop Insurance Ratemaking Procedures. Consulting report prepared for the Risk Management Agency. USDA. Kansas City, MO: USDA-Risk Management Agency.

Miranda, M.J., and J.W. Glauber. 1997. "Systemic Risk, Reinsurance, and the Failure of Crop Insurance Markets." American Journal of Agricultural Econonics 79:206-15.

Pinquet, J. 2000. "Experience Rating through Heterogeneous Models." In G. Dionne, ed. Handbook of Insurance. Boston: Kluwer Academic Publishers, pp. 459-500.

Turvey, C.G., M. Hoy, and Z. Islam. 2002. "The Role of Ex Ante Regulations in Addressing Problems of Moral Hazard in Agricultural Insurance." Agricultural Finance Review 62:103-16.

Watt, R., and F.J. Vazquez. 1997. "Full Insurance, Bayesian Updated Premiums, and Adverse Selection." The Geneva Papers on Risk and Insurance Theory 22:135-50.

Winter, R.A. 2000. "Optimal Insurance under Moral Hazard," In G. Dionne, ed. Handbook of Insurance. Boston: Kluwer Academic Publishers, pp. 155-83. 
addressing adverse selection and moral hazard problems in crop insurance. ${ }^{2}$

Nevertheless, the potential benefits of a discount system based on favorable insurance experience have not been lost to U.S. agricultural policy makers. In fact, Section 503(d)(3) of the Federal Crop Insurance Act (as amended in the Agricultural Risk Protection Act [ARPA] of 2000) states that

The [Federal Crop Insurance] Corporation may provide a performance based premium discount for a producer of an agricultural commodity who has good insurance or production experience relative to other producers of that commodity in the same area, as determined by the Corporation.

In light of this congressional authorization to implement such a discount, we investigate whether a properly structured experiencebased discount system might provide a method to better tailor rates to the unique experience of a particular agricultural producer. In theory, such adjustments could provide stronger incentives for producers to minimize losses, so that the discount could be maintained in future years. This mechanism could also potentially result in a more equitable rate structure for producers with differing levels of risk and could increase incentives for low-risk producers to participate in the program.

The objectives of this article are twofold: (a) to determine whether there is actuarial evidence to support implementation of a premium rate discount system for producers who have better-than-average loss (or production) experience and $(b)$ to develop a discount system that is practical and congruent with other aspects of the current rating system. Note that what is currently under consideration is a discount. The development of surcharges for producers with poor loss experience is not mentioned in Section 508(d)(3) of the Federal Crop Insurance Act (as amended in the ARPA of 2000) and is therelore not considered in this article; atthough the methods here could also be implemented for generating a discount/surcharge system.

\footnotetext{
2 Knight und Coble (1997), in an exitensive survey of tle literature from l980 to 1997 , did not mention any study that denlt wilh liscount systems in crop insurance. Based on our own research. we also lave not found any recent publishled st udies regnrding this issue.
}

\section{Conceptual Framework}

The theoretical basis for implementing experienced-based discounts is linked to the concept of making a posteriori premium rate adjustments so that premium rates can be better tailored to the unique experience of a particular insured. These a posteriori adjustments are typically based on the number and/or the magnittude of claims reported by the insured over successive insurance periods. Presumably, this historical claim experience provicles additional information about the insured's risk characteristics, such that premiums can be more accurately determined for each insured.

More formally, consider a portfolio of $n$ crop insurance policies for which we want to determine whether a posteriori adjustments are appropriate. Let $L C$ be a random variable representing the loss cost from any of the $n$ policies in the portfolio. Note that a loss cost is the ratio of indemnity to liability $(L C=$ indemnity/liability), which represents the relative dollar value of the yield loss (our main insurance outcome of interest). Since $L C$ is a random variable, it can be characterized by the distribution $f_{\theta}(L C)$ where $\theta$ is the variable that describes the risk characteristics of a particular insured and differs from one insured to another. The lower case theta $(\theta)$ can be thought of as a realization of a random variable $\Theta$, whose distribution is $g(\Theta)$. Thus, the risk process is divided into two parts: $(a)$ the " $\Theta$-lottery" where each time a person is insured $\theta$ is randomly drawn from the population $\Theta$ according to the distribution $g(\Theta)$ and (b) the " $L C$-lottery" governed by the distribution $f_{\theta}(L C)$.

Further, assume that the random variable $\Theta$ has observable and unobservable components. The observable components can be represented as $\mathbf{X}=\left\{X_{1}, X_{2}, \ldots\right\}$. In the crop insurance context, the set $\mathbf{X}$ may inclucle such individual characteristics as average yields, crop practice, crop type, etc. In addition, the "traditional" or "systemic" risk sources in crop insurance, such as adverse weather events and

\footnotetext{
${ }^{3}$ A posturiori premium rate adjustments are those adjustments made to the premium rates given that the individual has betn instred in the past. The adjustments tased in this case are based on apsitertiori vartables that were observed after the insurance policy has been in force. On the other hand, a prioni variables are those ubservable variables used to evalunte the risk of insured producers prior 10 the insurance policy being in force. These a priori varjables are typically used to set the initial (or a priori) premium rates.
} 
major pest infestations that affect a particular producer, can be characterized as part of the observable component of $\Theta$. For example, observable indicators like county-level historical weather patterns (i.e., to calculate the probability of adverse weather events) and countylevel historical pest damage can be thought of as part of the set $\mathbf{X}$. The unobservable components of $\Theta$ can then be represented as $\mathbf{Z}=$ $\left\{Z_{1}, Z_{2}, \ldots\right\}$, which, in crop insurance, can include managerial ability and unobserved effort, among others. Hence, $\Theta=\mathbf{X} \cup \mathbf{Z}$.

If the outcome of $\Theta$ is $\theta$ and assuming this realization is completely observable, an a priori premium can be set for this policyholder equaling $E[L C \mid \Theta=\theta]$. Since the premium is a function of a randomly drawn variable, the premium itself becomes a random variable. However, it is worth mentioning that even though the premium can be considered as a random variable, it is less dispersed than the $L C$ itself. In this case, the policyholder keeps the variations of the premiums due to the modification in his/her personal characteristics $\Theta$ and transfers to the insurance provider the purely randon fluctuations of $L C$. That is, the variance of the relative value of yield losses, once the personal characteristics $\mathbf{X}$ and $\mathbf{Z}$ have been taken into account, is transferred to the insurer.

Note, however, that the situation above is purely theoretical because in reality $\theta$ is not fully observable due to $\mathbf{Z}$. But we do have information about the observable $\mathbf{X}$-risk characteristics, which can be viewed as a vector-valued random variable. In this case, it is more likely that the insurer charges an a priori premium equivalent to $E[L C \mid \mathbf{X}=\mathbf{x}]$.

The idea behind the implementation of an experience-based discount system is that past claims or insurance performance reveals some of the hidden information in $\mathbf{Z}$. Let $L C^{\mathrm{H}}$ denote the historical experience about $L C$. The idea is that the information contained in $(\mathbf{X}$, $L C^{\mathrm{H}}$ ) becomes comparable to the information in $\Theta$ as time goes on. Thus, with an appropriate updating mechanism, the a posteriori premium that takes the historical experience into account can be written as $E\left[L C \mid \mathbf{X}, L C^{\mathrm{H}}\right]$. The residual variation of the expected $L C$ that is due to unobservable risk characteristics will be reduced with a posteriori premium adjustments (De Wit and Van Eeghen, 1984; Bermudez, Denuit, and Dhaene, 2001).

In mainstream insurance markets, such as automobile insurance, the updating mechanisms that have been used for a posteriori adjustments are typically based on either a
Bayesian framework or a regression framework. Bayesian approaches to upclating premium rates can be seen in stucties by Lemaire (1995) and Watt and Vazquez (1997), among others. Note that the regression approach to updating premiums in automobile insurance are typically based on count data models (e.g., Poisson and negative binomial models) because the main variable used to make a posteriori adjustments is counts of accidents (see Dionne and Vanasse, 1989, 1992). These count models are not directly applicable in the crop insurance context because we are typically interested in the magnitudes of yield losses and not just counts of losses. Hence, in this article, we propose a loss ratio regression approach to a posteriori updating of crop insurance premiums (based on historical experience).

In light of the general conceptual discussions above, it is important to relate these ideas in the context of premium rate setting in the U.S. Crop Insurance Program. Note that crop insurance is different from traditional lines of insurance because of the high degree of systemic risk in agricultural yield losses (Miranda and Glauber, 1997). Hence, proper implementation of a posteriori premium rate adjustments in crop insurance, which is based on historical experience, should be analyzed in accordance with the current premium rate setting proceclures used by the risk management agency (RMA), which takes this systemic portion into account.

From Milliman and Robertson, Inc. (2000), RMA's contintous rating formula can be expressed as

$$
\begin{aligned}
\text { (1) Base rate }= & {\left[U D F^{-1} \times\left[\left(\left[C U R \times\left(R_{y}\right)^{E}\right]\right.\right.\right.} \\
& \left.\left.\left.\times R F^{-1}\right)+F L\right]\right] \times C F
\end{aligned}
$$

where base rate is the unsubsidized base premium rate for the crop in the county, CUR the county unloaded rate, $R_{y}$ the yield ratio, $R F$ the reserve factor, $E$ the exponent (which is less than zero), FL the fixed catastrophic load, $U D F$ the unit division factor, and $C F$ the coverage level factor.

The key components of this continuous rating formula, as it relates to the concept of $a$ priori and a posteriori rate adjustments, are the $C U R$ and $R_{y}$. Note that the $C U R$ is an average of capped, county-level historical loss costs. It is calculated to reflect past county-level loss experience. Hence, the CUR can be thought of as an a posteriori adjustment mechanism 
aimed at using past county-level loss costs to bring more information about the "systemic risks" that all producers in a particular county are likely to experience. This crop insurance rating procedure implies that the a priori premium can be written as $E\left[L C \mid L C C_{\mathrm{C}}^{\mathrm{H}}\right]$, where $L C_{\mathrm{C}}^{\mathrm{H}}$ is the historical county-level loss cost experience. The historical county experience reveals information about both the observable and unobservable county-level characteristics that contribute to the systemic risks of producers in the county. Thus, if a producer's loss cost is perfectly correlated with the countylevel loss cost (i.e., his/her risks are clue only to systemic risks), then there is no need to use individual-level loss cost history to adjust premium rates because the county-level loss cost already provides this information.

Another important component of the RMA rating methodology is the yield ratio $R_{y}$. Note that $R_{\mathrm{y}}$ is the ratio of the insured's approved yield $(\bar{Y})$ and the county reference yield $\left(Y^{\mathrm{R}}\right): R_{\mathrm{y}}=\left[\bar{Y} / Y^{\mathrm{R}}\right]$. The insured's approved yield $(\bar{Y})$ is the simple average of the insured's historical yields (i.e., a four- to ten-year average yield) and the county reference yield is the average yield for the county. Together with the negative exponent $(E)$ in equation (1), the $R_{y}$ allows for "individualizing" the unloaded rates that were based on aggregate county-level experience. More specifically, individuals within the county that have mean yields lower than the mean county yield will have higher premium rates, while individuals with mean yields higher than the mean county yield will have lower premium rates. Note that this part of the crop insurance rating system uses individual mean yields as a basis for the "individualized" premium rates. Since insured producers' loss experience typically does not perfectly follow county-level experience, this "individualization" has been implemented to achieve more precise premium rates. The insured's mean yield, relative to the county average, can be thought of as an observable risk characteristic at the individual level that augments the county-level unloaded rates and makes the individual premium rate more accurate. This a priori premium rate adjustment can be written as $E\left[L C \mid L C_{C}^{\mathrm{H}}, X\right]$, where $X$ is the observable yield ratio.

Even with the role of $C U R$ and $R_{y}$ in the crop insurance rating system, it is important to note that individual-level loss experience is not being used in the current rating system to add more information about the individual producer's unobservable risk characteristics. Hence, there may be an opportunity to use information on individual loss experience to further refine the current crop insurance rating system. An experience-based discount system is an a posteriori adjustment that can be written in the crop insurance context as $E\left[L C \mid L C_{\mathrm{C}}^{\mathrm{H}}\right.$, $\left.X, L C_{\mathrm{I}}^{\mathrm{H}}\right]$, where $L C_{\mathrm{I}}^{\mathrm{H}}$ is a measure of the individual insured's loss experience. However, including this individual loss experience information in the rating system should not be duplicative of the adjustments based on CUR and $R_{y}$. That is, the experience-based discount system based on individual loss history should only add information with regard to the unobservable individual level or "idiosyncratic" risk of the producer.

\section{Empirical Methods and Data}

\section{Overview of the Empirical Approach}

Given that we are following the regressionbased updating framework, the conceptual discussion above naturally leads us to treat the problem as a classical "omitted variables" problem. Theoretically, we know that crop insurance premium rates, based on the current rating system, are actuarially fair only if they are an tunbiased estimate of the expected loss cost

$$
E[L C]=E\left[L C \mid L C_{\mathrm{C}}^{\mathrm{H}}, \mathrm{X}\right] .
$$

That is, the a priori crop insurance premium rates, $\left(E\left[L C \mid L C_{\mathrm{C}}^{\mathrm{H}}, X\right]\right)$, should conceptually be equal to the expected loss cost for a producer when there is no adverse selection and there is no additional information that is not contained in the $a$ priori crop insurance premium other than unpredictable random events.

If a factor, say $X_{2}$, does not belong to the premium rate structure, then a regression of actual loss cost experience on the premium rate and $X_{2}$ of the form

$$
\begin{aligned}
\text { Loss cost }= & \beta_{0}+\beta_{1} \text { premium rate } \\
& +\beta_{2} X_{2}+\varepsilon
\end{aligned}
$$

should yield the results $\beta_{0}=\beta_{2}=0$ and $\beta_{1}=1$. If $\beta_{0} \neq 0$ then either the rates are a biased predictor of the loss cost or the period over which loss cost is being measured is simply not reflective of longer-term loss experience. If appropriate statistical tests indicate that $\beta_{2} \frac{1}{T}$ 0 , then $X_{2}$ contains inlormation that is useful 
in predicting the loss cost and it is "omitted" in the current premium rate structure. The econometric implications of an omitted variable are not trivial. Particularly troubling is the potential bias in estimated parameters when there is an omitted variable (Greene, 2003). In this case, inclusion of $\mathrm{X}_{2}$ leads to a better prediction of expected loss cost, thus improving rate accuracy. As mentioned in the conceptual framework, if $X_{2}$ is an individual-level loss experience variable, then it may reveal information about the unobservable producer risk characteristics that were not previously included in the current crop insurance rating system.

Inclusion of a previously omitted variable is consistent with proper implementation of an experience-based discount structure in crop insurance because, in this case, one is attempting to augment the current rate structure with an additional individual-level "experience" variable rather than reestimate an existing relationship. This means that an omitted "experience" variable $\left(X_{2}\right)$ to be included in the regression equation should provide appropriate rate corrections for good experience in a way that cloes not incorporate imperfections in other factors that are already included in the rating system. Any imperfection in a factor already included in the rating system-e.g., optional units, $t$-yields, and number of years of actual yields, for example-should be corrected for all producers, not incorporated into an experience-based rate discount that only applies to a subset of producers meeting a set of qualifying criteria. Thus, it is important that the experience variable $X_{2}$ is not a factor already included in the current premium rate. Having an $X_{2}$ that is already included in the premium would result in a "spurious" regression for estimating good experience discounts of the form

$$
\begin{aligned}
\text { Loss cost }= & \beta_{11}+\beta_{1} \text { premitum rate }\left(X_{2}\right) \\
& +\beta_{2} X_{2}+\varepsilon .
\end{aligned}
$$

In this case, what is tested is not whether $X_{2}$ is "omitted," but whether loss cost experience suggests that it is correctly incorporated into the current premium rate. Again, as emphasized above, statistical significance of $\beta_{2}$ would indicate a need to correct the rating system for all producers, and should not be interpreted as a separate "experience-based" factor, applicable only to a subset of qualifying proclucers.
The specification in equation (3) serves as the foundation of our empirical approach. This specification shows whether an "omitted" variable that is an indicator of experience adds more information to the current premium rates and better reflect expected losses. And if the experience variable does indeed add more information, one can incorporate this factor directly into the current rating system to generate discounts for qualifying producers who have shown better-than-average insurance performance.

\section{Measures of Good Experience}

In estimating equation (3) above, the first issue that needs to be addressed is the choice of an appropriate indicator of "good experience" $\left(X_{2}\right)$ upon which to base the discount. Three measures of "good experience" are considered in this study: a loss ratio index ( $L R I)$, a yield variance index $(Y V I)$, and number of years of continuous participation ( $N Y C P$ ).

The $L R I$ in this article is based on a comparison of a five-year historical loss ratio of an individual insured producer, relative to the loss ratio for all producers of the same crop type and practice in the county, over the same period. Our index can be mathematically represented as

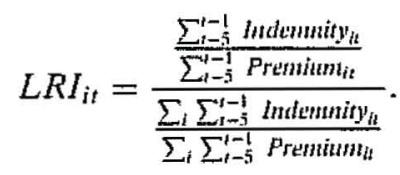

The numerator in (5) is the historical loss ratio of individual $i$ over the five-year period $t-1$ through $t-5$, and the clenominator is the corresponding five-year loss ratio of all producers in the county producing the same crop type and following the same practice. The $L R I$ allows us to gauge whether an individual has "good" loss experience compared to a peer group that has a similar growing environment.

Our $L R I$ experience measure only applies to producers who have five years of participation. This means that the producer can be tracked in the RMA data base for five consecutive years and has grown the same crop type, using the same practice, over that period. Importantly, it requires five years of experience at the crop type and practice level only. Thus, it allows for the possibility that a producer with multiple insured units may have followed a crop rotation system, not necessarily growing the same crop on an insured unit in every year. 
The choice of five years is arbitrary but reflects a balance between a longer period (that would have greater statistical power) and choosing a shorter period (that would make it possible for more producers to qualify but - would have lower statistical power). We investigated other timeframes for the $L R I$ and calculated the proportion of the insurance pool that could be traced across years. Approximately, 20-30\% of the insurance pool for corn, soybean, cotton, and wheat policies would meet this five-year criterion. If current participation trends continue, then the proportion of producers that can be tracked for five years will likely increase.

Another measure of good experience considered is the $Y V I$. Using yield variance as a measure of favorable loss experience is based on the concept that a producer who has a lower yield variance than his/her peers is less risky and would have lower expected insurance losses (Goodwin, 1994). Hence, YVI is defined as the ratio of an individual producer's ten-year yield variance to a weighted average yield variance for other producers of the same crop type and practice in the county. Mathematically, the $Y V I$ can be represented as follows:

$$
Y V I_{i t}=\frac{\sum_{t-10}^{t-1}\left(Y_{i t}-\bar{Y}_{i}\right)^{2}}{\sum_{i=1}^{n} \omega_{i} \sum_{t-10}^{t-1}\left(Y_{i t}-\bar{Y}_{i}\right)^{2}}
$$

where $i$ is the individual observation, $n$ the number of observations in the county, $t$ the current year, $\omega$ a weight based on reported number of acres for each individual, and $Y$ the yield reported by the producer (found in the yield record for year $t$ ). An individual producer has to have ten years of actual yields (for the same crop type and practice) reported in the yield history record to qualify for an experience-based discount using the YVI. Ten years of yield history is the maximum reported in the RMA data system, and this should be the minimum requirement in order to construct the most credible yield variance estimates possible.

Another good experience measure considered is the $N Y C P$. This experience variable is the number of years an individual producer can be traced as having continuously participated in the crop insurance program (for a specific crop type and practice). More specifically, years of continuous participation for the previous eight years were used. The appealing aspect of this type of experience variable is its simplicity-it does not require a peer group for comparison. Note that this measure qualifies as a good experience variable only when it is assumed that a producer who continuously participates in the program (for the same crop type and practice) is more likely to have good insurance experience. However, it is possible that some continuous participants may also have bad experience. Hence, the advantage of NYCP's simplicity is tempered by this potential weakness.

\section{Estimation Procedures}

With the three "good" experience measures $\left(X_{2}\right)$ above, we could have proceeded by econometrically estimating equation (3). However, there is a limitation to estimating this equation directly. As specified, the effect of $X_{2}$ is an additive factor to be added to the current premium rate. While this could be workable, there are several reasons to consicler a multiplicative factor. Foremost is that most other rate factors in the crop insurance rating formula are multiplicative, allowing the magnitude of the discount or surcharge to be scaled by the base premium rate. This procedure may also reduce the potential heteroskedasticity in equation (3). To estimate a multiplicative performance factor, the loss cost is scaled by the "effective" premium rate $(E P R)$, where $E P R=$ total premium/liability. This leads to the estimation of a loss ratio (indemnity/ premium) model, rather than a loss cost model, at the individual producer, crop type, and practice level. Dividing the loss cost by the EPR means that (indemnity/liability)/(total premiums/liability) $=$ indemnity/total premiums $=$ loss ratio.

The loss ratio model may then be written as ${ }^{4}$

$$
\text { Loss ratio }=\beta_{0}+\beta_{1} X_{2}+E \text {. }
$$

\footnotetext{
"One reviewer questioned whether this spectification could cause a "spurious regression" because the denaminator of the loss ratio in the left-hand side of the equation (i.e., the premium in year $t$ ) and the numerator of the $L R I$ in the right-land side of the equattion (i.e., the indemnity and premium in years $t-5$ to $t-1$ ) are hoth partly determined by past yiels realizutions. Although not reported here, we could show that if the regression in equation (7) is "spurious" (dute to past yjeld realizntions partly affecting hoth sides of the equation), then the logical expected sign from this "spurious regression" shauld be is statistically significan negative $\beta_{1}$ cotlficient. But as can be seen in our results, this is not the case (i.e., the estimated $\beta_{1}$ coefficient is positive and significunt). Hence. by contradiction, past yield realizations alfecting both the left-and riglit-hand terms of equation (7) do not seem to be strong enougl to cause il "spurious" redationslip to be produced.
} 
In this formulation, an outcome of $\beta_{0}=1.0$ and $\beta_{1}=0$ would imply an actuarially sound program with the $X_{2}$ failing to add additional information beyond that contained in the current rates. If $\beta_{1} \neq 0$, the $L R I$ is adding information to current rates in explaining historically observed loss ratios. Year dummy variables are also added to the model to control year effects.

The loss ratio is censored so tobit model estimation procedures are used. Expected values of the dependent variables in such a case are given by

$$
E[Y]=\Phi \times(X \beta+\sigma \varphi / \Phi)
$$

where $\Phi$ and $\varphi$ are the normal cumulative distribution function (cdf) and normal probability density function (pdf), respectively, evaluated at $X \beta / \sigma$, and $X \beta$ is the index implied by the product of the explanatory factors and the estimated parameters from the tobit model. Note that estimation was performed at different levels of geographical aggregation. For example, equation (7) was estimated at both the national and several regional levels for each crop. Estimating the models for different regions potentially controls for geographic heterogeneity in the data. Once the parameters of equation (7) and the coefficients associated with the year dummy variables are estimated, the multiplicative "good" experience discount factor can be calculated (as discussed in the next section).

\section{Data Description and Development}

The empirical modeling of experience-based premium rate discounts utilized the extensive experience data available in the RMA's participation data base. Unit-level policy, acreage, yield, and loss record files were available for four major crops, for the period 1991-2002. The crops considered were corn, wheat, cotton, and soybeans. Data for the actual production history yield insurance plan, the revenue assurance, and crop revenue coverage insurance plans were included. The relevant variables for the calculation of the experience-based discount are aggregated at the tax ID, crop type, and practice level, which allows for differing experience-based discounts for a producer across alternative production systems within each crop, such as dryland cotton versus irrigated cotton.
Table 1. Parameter Estimates Associated with the Three Alternative "Good" Experience Measures Using the National Data Set (Dependent Variable: Loss Ratio)

\begin{tabular}{lc}
\hline Crop/Index & $\begin{array}{c}\text { Parameter } \\
\text { Estimate } \\
\text { from the } \\
\text { Tobit Model }\end{array}$ \\
\hline Corn & \\
LRI & \\
$Y V I$ & $0.3109^{*}$ \\
NYCP & $0.2629^{*}$ \\
Soybeans & $0.0126^{*}$ \\
LRI & \\
YVI & $0.3185^{*}$ \\
NYCP & $0.1651^{*}$ \\
Cotton & $0.3631^{*}$ \\
LRI & \\
$Y Y I$ & $0.2378^{*}$ \\
$N Y C P$ & -0.0176 \\
Wheat & $0.1544^{*}$ \\
LRI & \\
$Y V I$ & $0.2644^{*}$ \\
$N Y C P$ & $-0.0581^{*}$ \\
\hline
\end{tabular}

$L R I=$ loss ratio index: $\gamma V /=$ yital veriunce index: $N \gamma^{\prime} C r=$ mutther of years of contirusus participation.

Asterisks (*) demote significante at the $1 \%$ level.

\section{Results and Discussion}

The first issue that needs to be addressed in developing the discount system is the choice of experience measure. To determine what measure performs best, we estimated the loss ratio model using the different measures of experience (at the national level) and compared the resulting parameter estimate associated with each experience measure. Table 1 presents the tobit model parameter estimates for each "good" experience measure we investigated. ${ }^{5}$ The first thing to note is the positive sign associated with the $N Y C P$ parameter estimate for all crops. This is not consistent with a priori expectations that longer participation leads to lower loss ratios (i.e., better production experience). The positive sign implies that, all else equal, units with longer continuous participation tend to have higher loss

\footnotetext{
5 In the interest of space, we only prestent the parameter comparisons using the national data. The comparisons for the other regions are very sinilar and are nvailable from the authors upon request. In addition, in the interest of space, all regional model results (i.e., the purameter estimates and discount factors) for the different good experience measures are also not tuported here, hut they are avilibule from the authors upon reçuest.
} 
ratios. Hence, insured producers with long participation histories should, on average, receive surcharges rather than discounts. When we investigated this issue further, it seems that there are nontrivial percentage of continuous participants that have poor loss experience relative to their peers. This suggests that $N Y C P$ as a criterion for performance-based discounts is not recommended.

The YVI parameter estimate for corn and soybeans, on the other hand, has a sign that followed a priori expectations (table 1). The parameter estimate is statistically significant at the $1 \%$ level as well. However, this result is not robust across all crops and regions. Cotton and wheat, for example, have negative YVI parameter estimates using the national data. Most of the regional model results for cotton and wheat also consistently showed that the $Y V I$ parameter estimates were negative. Although the $Y V I$ parameters estimated for corn and soybeans have a statistically significant and positive sign at the national level, this is not consistently the case at the regional level. The signs and significance of the $Y V I$ parameter at the regional level were very inconsistent for corn and soybeans. These results suggest that the $Y V I$ is a relatively unreliable criterion to use as the basis for calculating experience-based discounts.

The results in table 1 also indicate that the $L R I$ parameter for corn at the national level follows a priori expectation- $-L R I$ and loss ratios should have a positive and significant relationship. But unlike the YVI measure, this result is robust across all the crops and regions considered. This result suggests that the $L R I$ is a more robust measure of historical insurance performance that could be implemented on a broad scale.

The summary statistics for the $L R I$ variable used in the tobit estimation of equation (3) for corn, soybeans, cotton, and wheat (using the national data) can be seen in table 2. This table shows the mean and variability of the insurance performance measure used for setting the experience-based discount. The parameter estimates from the tobit estimation procedures for the national level com, soybeans, cotton, and wheat data, are presented in table 3. For all crops, the parameter estimates associated with the $L R I$ are consistently positive and statistically significant ( $p$-value $<0.0001)$. This means that the $L R I$ experience variable indeed adds more information to explain the observed loss ratio of the individual and that a premium rate discount based on this experience variable may be appropriate.
Table 2. Summary Statistics of the Loss Ratio Index for Corn, Soybeans, Cotton, and Wheat (National Data Set)

\begin{tabular}{llll}
\hline Crop/Varinble & Mean & Std. Dev. & Max. \\
\hline $\begin{array}{l}\text { Corn }(N=444.419) \\
\quad L R I\end{array}$ & 0.8327 & 1.9356 & 1.13 .9100 \\
$\begin{array}{l}\text { Soybeans }(N=386,991) \\
\quad L R I\end{array}$ & 0.8062 & 2.0169 & 123.3341 \\
$\begin{array}{c}\text { Cotton }(N=86,900) \\
\quad L R I\end{array}$ & 0.9136 & 0.9477 & 21.2368 \\
$\begin{array}{l}\text { Wheat }(N=169,634) \\
\quad L R I\end{array}$ & 0.8524 & 1.2873 & 42.1000 \\
\hline
\end{tabular}

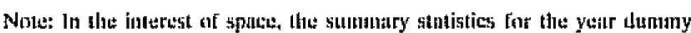

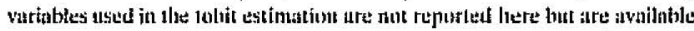
from tlite atulpurs tipon requtest.

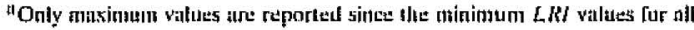
cropts inte zero.

Using the parameter estimates in table 3, one can estimate the proper multiplicative discount factor for insured producers with good loss experience relative to the county average. This is done by predicting the expected loss ratio when the $L R I$ is equal to 1.0 and comparing this to the expected loss ratio using the actual $L R I$ of the individual. Thus, the multiplicative factor is a ratio of the expected loss ratio of the individual based on his/her actual $L R I$ over the expected loss ratio for an individual with iclentical characteristics with an $L R I$ of 1.0. Following the calculation of the expected or predicted loss ratio in equation (8), the multiplicative factor can be mathematically computed as follows:

$$
\begin{aligned}
& \text { Multiplicative factor } \\
& =\frac{E\left[\text { loss ratio } \mid L R I=L R I_{i}\right]}{E[\text { loss ratio } \mid L R I=1.0]} \\
& =\frac{\Phi_{i} \times\left[\left(\beta_{1} \cdot L R I_{i}+\beta_{2} D\right)+\left(\frac{\pi \varphi_{i}}{\Phi_{i}}\right)\right]}{\Phi_{1} \times\left[\left(\beta_{1} \cdot 1+\beta_{2} D\right)+\left(\frac{\sigma \phi_{1}}{\Phi_{1}}\right)\right]}
\end{aligned}
$$

where $\Phi_{i}$ and $\varphi_{i}$ are the normal cdf and pdf evaluated at $\beta_{1} \cdot L R I_{i}+\beta_{2} D ; \Phi_{1}$ and $\varphi_{1}$ are the normal cdf and pdf evaluated at $\beta_{I} \cdot 1+$ $\beta_{2} D ; L R I_{i}$ is the actual $L R I$ calculated for individual $i ; D$ is the vector of year dummy variables; $\beta_{1}$ is the estimated parameter associated with the $L R I$ variable; and $\beta_{2}$ is the vector of parameter estimates associated with the year dummy variables.

This reflects the adjustment in the premium rate that would equalize loss ratios between producers with good experience $(L R I<1.0)$ and producers with experience equal to the 
Table 3. Tobit Regression Results for Corn, Soybeans, Cotton, and Wheat Using the National Data Set (Dependent Variable: Loss Ratio)

\begin{tabular}{|c|c|c|c|}
\hline Crop/Variable & $\begin{array}{l}\text { Coefficient } \\
\text { Estimate }\end{array}$ & $\begin{array}{l}\text { Std. } \\
\text { Error }\end{array}$ & $p$-Value \\
\hline \multicolumn{4}{|l|}{ Corn } \\
\hline Intercept & -3.0702 & 0.0258 & $<0,0001$ \\
\hline$L R I$ & 0.3109 & 0.0052 & $<0.0001$ \\
\hline Year96 & -2.3490 & 0.1430 & $<0.0001$ \\
\hline Year97 & -3.9832 & 0.0453 & $<0.0001$ \\
\hline Year9s & -2.8380 & 0.0427 & $<0.0001$ \\
\hline Year99 & -2.3712 & 0.0384 & $<0.0001$ \\
\hline Year00 & -3.4501 & 0.0352 & $<0.0001$ \\
\hline Year01 & -2.1821 & 0.0346 & $<0.0001$ \\
\hline \multicolumn{4}{|l|}{ Soybeans } \\
\hline Intercept & -3.6762 & 0.0268 & $<0.0001$ \\
\hline$L R I$ & 0.3185 & 0.0049 & $<0.0001$ \\
\hline Yearst & -2.3824 & 0.1607 & $<0.0001$ \\
\hline Year97 & -3.2710 & 0.0483 & $<0.0001$ \\
\hline Year98 & -2.2454 & 0.0461 & $<0.0001$ \\
\hline Yetarg9 & -1.4459 & 0.0400 & $<0.0001$ \\
\hline Year0o & -0.7256 & 0.0319 & $<0.0001$ \\
\hline Year01 & -1.0444 & 0.0340 & $<0.0001$ \\
\hline \multicolumn{4}{|l|}{ Cotton } \\
\hline Intercept & -1.4450 & 0.0405 & $<0.0001$ \\
\hline$L R I$ & 0.2378 & 0.0146 & $<0.0001$ \\
\hline Year96 & 2.0619 & 0.1292 & $<0.0001$ \\
\hline Year97 & -1.4078 & 0.0567 & $<0.0001$ \\
\hline Year9s & 1.7912 & 0.0502 & $<0.000 t$ \\
\hline Year99 & 0.4827 & 0.0502 & $<0.0001$ \\
\hline Year00 & 1.1975 & 0.0464 & $<0.0001$ \\
\hline Year01 & 0.9186 & 0.0502 & $<0.0001$ \\
\hline \multicolumn{4}{|l|}{ Wheat } \\
\hline Intercept & -1.2249 & 0.0315 & $<0.0001$ \\
\hline$L R I$ & 0.2644 & 0.0113 & $<0.0001$ \\
\hline Year96 & -3.9476 & 1.3387 & 0.0032 \\
\hline Year97 & -3.8427 & 0.1529 & $<0.0001$ \\
\hline Yeargs & -3.4119 & 0.1493 & $<0.0001$ \\
\hline Year99 & -2.5099 & 0.0479 & $<0.0001$ \\
\hline Year00 & -2.7317 & 0.0404 & $<0.0001$ \\
\hline Year01 & -1.3430 & 0.0407 & $<0.0001$ \\
\hline
\end{tabular}

Notu: Hase ytar ansited from retgression is zno?

average for the county $(L R I=1.0) .^{6}$ Hence, this is the factor that would be multiplied by the premium rates of producers with good experience. For example, a factor of 0.90 means that the individual had favorable loss experience (relative to the county) and that the indiviclual merits a $10 \%$ discount.

\footnotetext{
"As we have mentioned in the introduction, the metlods in this article could also be utilized to generite a surcharge scheme if needed. Specilically. a multiplicative surciarige factor can be calculated in a straightforward manner by comparing the expected loss ratio of producers with bad experitute (i.t., $L R I>1.0$ ) and a productr with experience equal to the average for the councy $(L R]=I,[)$.
}

Note, that this factor would be multiplied after the base rate for the qualifying producer has been calculated (as in equation (1)). Thus, producers with higher coverage levels would inherently have a higher absolute cliscount as compared to producers at a lower coverage level (even if they both have the same discount factor) because the premium rate for the high coverage level producer would typically be higher in absolute terms. That is, the coverage level factor in (1) for high coverage level producers would be higher than low coverage level producers, resulting in a higher base rate and, consequently, the benefit from a discount would be greater.

The predicted mean discount factors for qualifying producers using national level data are $0.91,0.91,0.95$, and 0.94 for corn, soybeans, cotton, and wheat, respectively. This implies that, on average, a corn or soybean producer with five years of good experience will receive a $9 \%$ premium discount. A cotton producer with the same five-year favorable loss experience would receive a $5 \%$ discount on average, while a wheat producer would receive a $6 \%$ discount.

To assess the sensitivity of the average discount estimates, the percentiles of these good experience discount factors (based on the national level data) are reported in table 4. For conciseness, the regional percentiles for each crop are not presented here but are available from the authors upon request. While it is common to only report averages, we chose to report the 5th, 10th, 25th, 50th, 75th, 90th, and 95th percentiles of all individual results, in order to revenl outliers. This is done because it is possible to derive a procedure that works in

Table 4. Percentiles of Predicted Good Experience Discount Factors for Corn, Soybean, Cotton, and Wheat (Using the National Data Set)

Predicted Multiplicative Discount Factors

\begin{tabular}{lcccc}
\cline { 2 - 5 } Percentile & Corn & Soybeans & Cotton & Wheat \\
\hline 95th & 0.9801 & 0.9766 & 0.9956 & 0.9902 \\
90th & 0.9626 & 0.9566 & 0.9913 & 0.9811 \\
75th & 0.9193 & 0.9097 & 0.9781 & 0.9573 \\
50th (median) & 0.9005 & 0.8961 & 0.9490 & 0.9287 \\
25th & 0.8961 & 0.8937 & 0.9183 & 0.9165 \\
10th & 0.8920 & 0.8844 & 0.9110 & 0.9110 \\
5th & 0.8920 & 0.8764 & 0.9059 & 0.9110 \\
\hline
\end{tabular}

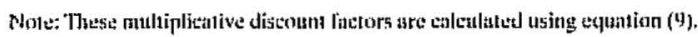

